\title{
A EMERGÊNCIA DO CONCEITO DE REGIÃO METROPOLITANA COMO UNIDADE DE PLANEJAMENTO
}

Julio Cesar Botega do Carmo ${ }^{1}$

Resumo: A emergência da discussão metropolitana na segunda metade do século $\mathrm{XX}$, sobretudo nos países em desenvolvimento, tem sido alvo de diversas pesquisas e análises. Assim, as regiões metropolitanas são estudadas sob seus aspectos econômicos, sociais, demográficos, ambientais, entre outros, entretanto, como tal conceito circulou e foi incorporado em distintas realidades permanece um caso a ser debatido. Neste texto, a partir da sistematização realizada do levantamento bibliográfico, busca-se definir como surge tal recorte de planejamento, se atendo à origem de tal conceito e como ele foi apropriado para diferentes realidades.

Palavras-chave: Região metropolitana. Unidade de planejamento. Planejamento metropolitano.

\section{RISE OF THE CONCEPT OF METROPOLITAN AREA LIKE AS PLANNING UNIT}

Abstract: The emergence of metropolitan discussion in the second half of the twentieth century, particularly in developing countries, has been the subject of several studies and analyzes. The historiographical point of view, however, the movement of certain ideas and concepts was not as exploited, particularly in Brazil, including what we conventionally call "region" or "metropolitan area". Thus, metropolitan regions have been studied in their economic, social, demographic, environmental, among others, however, as the concept was circulated and was incorporated in different realities remains a case to be discussed. This text seeks to define how arises such crop planning, sticking to the origin of the concept and how it was appropriate to different realities.

Keywords: Metropolitan region. Planning unit. Metropolitan planning.

\section{LA EMERGENCIA DEL CONCEPTO DE REGIÓN METROPOLITANA CÓMO UNIDAD DE PLANIFICACIÓN}

Resumen: La emergencia de la discusión metropolitana en la segunda mitad del siglo XX, sobre todo en los países en desarrollo, ha sido objeto de diversas investigaciones y análisis. Así, las regiones metropolitanas son estudiadas bajo sus aspectos económicos, sociales, demográficos, ambientales, entre otros, sin embargo, como tal concepto circuló y fue incorporado en distintas realidades sigue siendo un caso a ser debatido. En este texto, a partir de la sistematización realizada del levantamiento bibliográfico, se busca definir como surge tal recorte de planificación, atendiendo al origen de tal concepto y cómo fue apropiado para diferentes realidades.

Palabras clave: Región metropolitana. Unidad de planificación. Planificación metropolitana.

1 Instituto Federal do Paraná, Campus Campo Largo, Brasil, juliobotega@yahoo.com.br, https://orcid.org/0000-0003-0802-8393 


\section{Introdução}

O início da problemática do planejamento metropolitano pode ser pontuado quando das primeiras discussões acerca do planejamento regional e sobre as teorias regionais, especialmente os clássicos de Johann Heinrich Von Thunen (1783-1850, figura 1), Ernest Burgess (1886-1966), Walter Christaller (1893 - 1969, figura 2) e François Perroux (1903-1987), entre outros. Com exceção do primeiro, os demais são contemporâneos à discussão sobre a delimitação de regiões de planejamento que tem a metrópole como centro, na virada do século XIX para o XX.

Figuras 1 e 2: Modelo de renda agrícola de Von Thunen e Teoria das localidades centrais de Chistaller

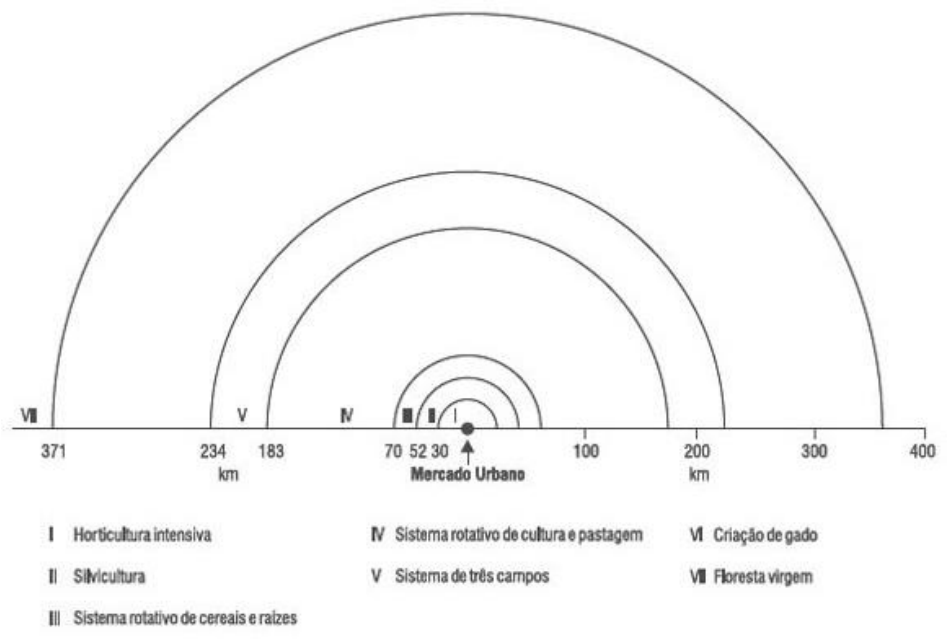

Fonte: Cabral, 2011; Benko, 1998.

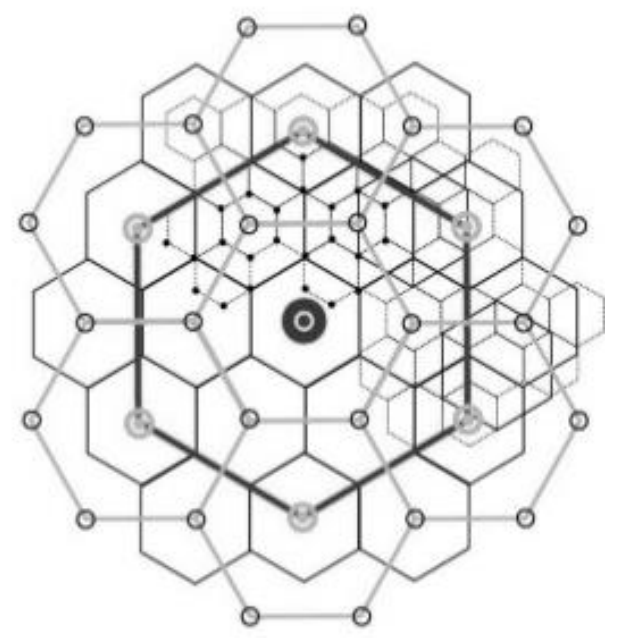

Além das teorias concebidas pelos geógrafos, economistas e sociólogos, Peter Hall (2013), entre outros autores, reconhece que o planejamento regional teve origem nos escritos de Patrick Geddes (1854-1932), biólogo britânico que influenciou de forma indelével a experiência norte-americana, seja via a Regional Planning Association of America (RPAA) ${ }^{2}$, ou por meio do Plano Regional de Nova York (PRNY), de Thomas Adams (1871-1940).

\footnotetext{
2 De acordo com Dal Co (1975, p. 245) "a Regional Planning Association of America (RPAA) foi um grupo de personagens com diferentes formações que, com sua ideologia e sua obra, foi o melhor intérprete, em nosso campo, do compromisso reformista entre o final da Primeira Guerra Mundial e os anos trinta. (...) Os membros que a constituem são a extrema expressão da continuidade e homogeneidade da tradição cultural norte-americana, e é partindo desta tradição que representam a síntese e a união física entre as exigências teóricas originadas na 'era progressista', as esperanças e experiências da 'economia de guerra', a síntese final do New Deal." (Traduzido da versão em espanhol pelo autor)
} 
O interesse nos ensinamentos de Geddes e seus discípulos se assenta sobre sua influência no modelo americano de planejamento regional, pois sendo a RPAA a grande propagadora das ideias de Geddes - sobretudo por meio de Lewis Mumford (1895-1990) e ao influenciar grandes projetos de desenvolvimento regional, como a Tennessee Valley Authority (TVA, figura 3) -, e a contribuição do PRNY (figura 4) como plano elaborado para três estados a partir da irradiação da urbanização e do extravasamento e conexão de uma série de metrópoles, depreende-se que são elementos chave para a compreensão destas enquanto propulsoras de um processo que está além da clássica divisão cidade-campo e que por isso demanda uma nova dimensão e diferenciação nas análises.

Figura 3: Área de Planejamento da TVA

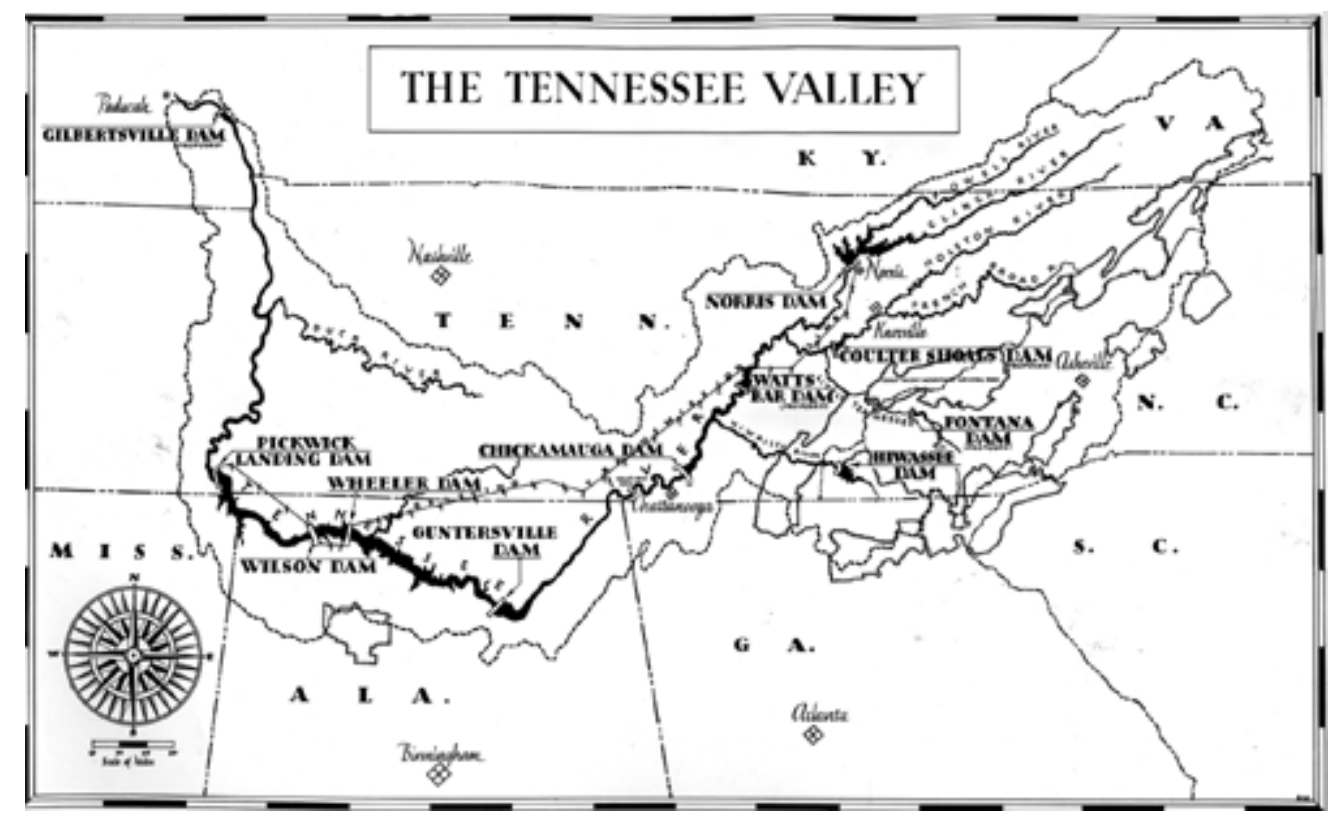

Fonte: New Deal Network, 2015. 
Figura 4: Localização do Plano Regional de Nova York

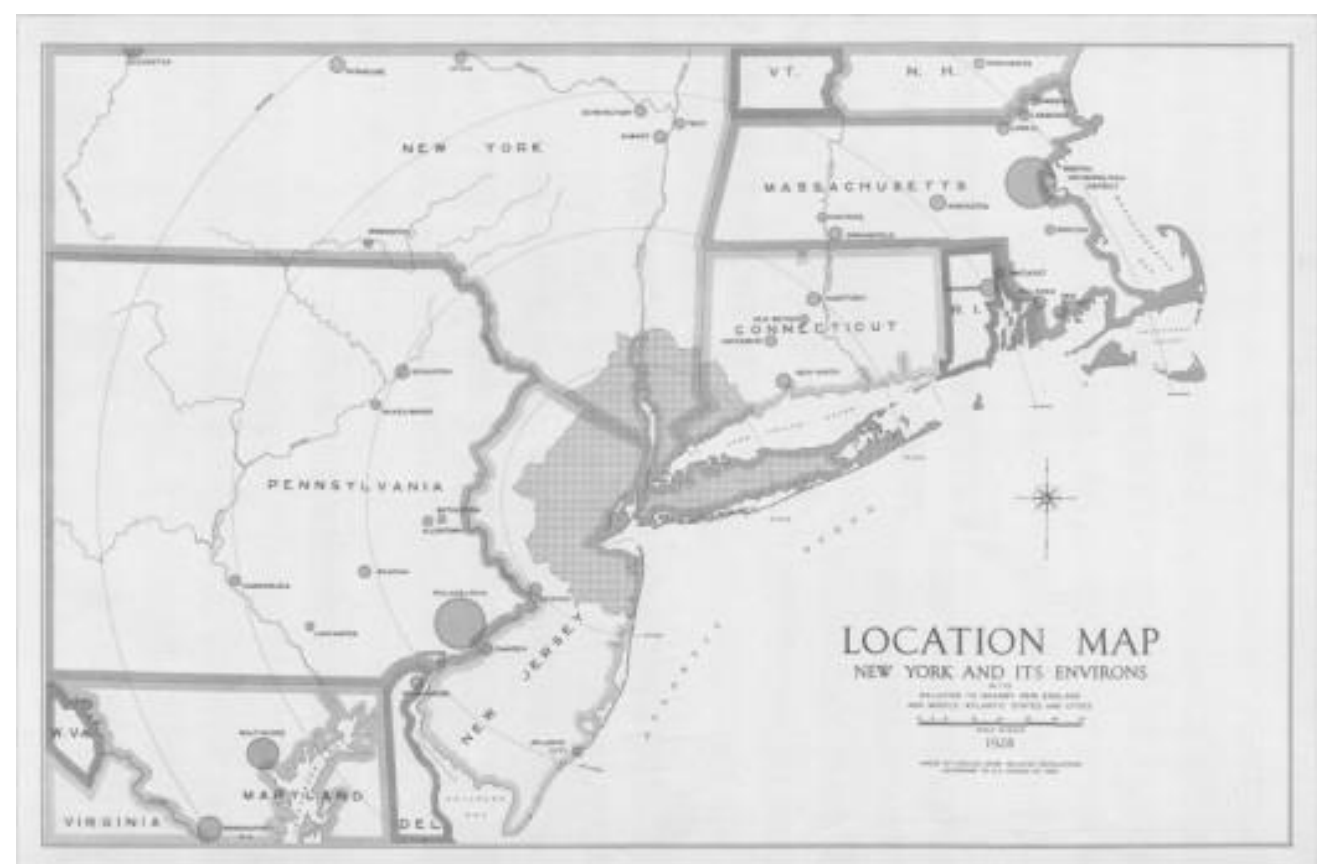

Fonte: Urban Omnibus, 2010.

Dessa forma, o objetivo deste texto é traçar um panorama sobre o surgimento do conceito de região ou área metropolitana, entendida como área polarizada por uma metrópole. Diferenciada em escala, forma e função do conceito de cidade entendida como área urbana-, o alcance das diversas relações em um espaço supramunicipal circunscrito, permite definir a região metropolitana como unidade de planejamento. Busca-se assim a partir do levantamento bibliográfico e da historiografia, propor uma discussão que tenha a escala metropolitana como fundamento, pois esta geralmente é menos referenciada nos estudos, que se atém principalmente a processos locais, regionais ou globais. A partir de três perspectivas analíticas, propõe-se compreender como se deu o reconhecimento da região metropolitana como recorte territorial no hemisfério ocidental. Estas perspectivas seriam dos planos metropolitanos, das instituições de planejamento metropolitano e, sobretudo, da delimitação das áreas metropolitanas como unidades de planejamento.

Neste sentido, de acordo com Rodriguez e Oviedo (2001), ainda que áreas metropolitanas remetam geralmente à ideia das grandes cidades (metrópoles em sentido econômico e/ou populacional), interessa nesta análise não seu sentido quantificável, mas, sobretudo, como estas aglomerações urbanas complexas que agregam diferentes recortes territoriais e administrativos, constituem uma, nem sempre eficaz, unidade de funcionamento e gestão. 


\section{REGIÃO METROPOLITANA COMO UNIDADE DE PLANEJAMENTO}

A origem da delimitação e do planejamento específico das áreas metropolitanas, em substituição ao genérico e amplo "planejamento regional", se deu quando o fato urbano da cidade polo ultrapassou seus limites municipais não apenas territorialmente, mas também social, institucional e administrativamente, levando à proliferação de periferias autônomas e conurbações, pois ao mesmo tempo em que agregou diferentes unidades sob o ponto de vista econômico, permaneceu fragmentado (LENCIONI, 2011). As repercussões de tal pulverização foram o surgimento de problemas de coordenação e sobreposição de competências, escamoteando vantagens comparativas da aglomeração urbana.

Há uma dificuldade em diferenciar o que seria o planejamento metropolitano do regional, uma vez que sendo o regional passível de múltiplas e diferentes interpretações, como aponta Gomes (2008), o metropolitano não deixa de ser uma região. Tenta-se, entretanto, estabelecer o metropolitano enquanto escala territorial e política, definida pelo fenômeno da metropolização, mas, sobretudo pela institucionalização e delimitação legal da região metropolitana. $O$ planejamento metropolitano se coloca dessa forma entre o planejamento urbano, considerado local, e o planejamento regional, de maior amplitude territorial, uma vez que não abarca apenas a área urbanizada, mas também o entorno rural e mesmo as conexões com outras regiões, metrópoles, cidades etc.

Assim, faz parte também do escopo deste texto apresentar as primeiras tentativas internacionais de planejar, institucionalizar e delimitar as áreas metropolitanas, com foco nos planos e nas instituições de planejamento.

Os planos de expansão urbana das metrópoles se iniciaram a partir de 1850, em cidades como Paris (1857), Viena (1858), Barcelona (1859, figura 5), Berlim $\left(1862^{3}\right)$, entre outras. Não se caracterizaram, porém, como planos centrados na metrópole como polo de uma rede urbana. As pioneiras experiências de planejamento tendo metrópoles como centro urbano regional foram os trabalhos realizados para o Plano de Chicago (1909), de Daniel Burnham, do Plano Regional de Nova York (1930), de Thomas Adams, e do Plano do Condado de Londres (1944), que teve consultoria de Patrick Abercrombie, entre outros. Assim, os planos

${ }^{3}$ De acordo com Quinto Jr. (1990, p. 64): "O urbanismo alemão é o primeiro a elaborar uma legislação urbana específica para regulamentar a expansão urbana (Plano de Berlim, 1862)", mas como indicado, várias cidades europeias tiveram planos de expansão anteriores. 
metropolitanos antecedem nestes casos a institucionalização e mesmo o recorte da região metropolitana como unidade de planejamento.

Quanto à preocupação de uma forma de gestão que centralizasse o planejamento metropolitano, de acordo com o arquiteto e planejador teutocanadense Hans Blumenfeld (1956), a área metropolitana de Toronto foi a primeira no Ocidente a ter uma política oficial que reconhecia o fato urbano gerado pela sociedade industrial moderna como uma nova forma de assentamento humano.

Portanto, a institucionalização do planejamento metropolitano iniciou-se no Canadá, com a fundação, em 1953, da Metropolitan Toronto e a definição do Município Metropolitano de Toronto, em 1954. Ainda que em outros países já existissem políticas neste sentido, como nos EUA, onde as Metropolitan Planning Organizations eram responsáveis pelas políticas rodoviárias e de transportes, estas eram setorizadas e não de planejamento compreensivo, característico das agências metropolitanas que surgiriam a partir da década de 1950. Boothroyd (2010) coloca que a Metropolitan Toronto, foi criada como organização administrativa, como novo nível de governo pela Província de Ontário, que permitiu aos treze governos municipais manter a prestação de serviços locais ${ }^{4}$, enquanto as funções regionais ${ }^{5}$ passaram à administração da nova entidade.

O primeiro plano para uma região metropolitana realizado por uma instituição metropolitana foi o elaborado pela Metropolitan Toronto, em 1959, com análises sobre a área metropolitana de Toronto, tendo como um de seus produtos o mapa da área metropolitana que pode ser visto nas Figuras 5 e 6 , que mostra o então Município Metropolitano de Toronto e os municípios que formavam seu entorno rural, cidades e vilas.

\footnotetext{
${ }^{4}$ Combate a incêndios, bibliotecas e abertura de ruas, por exemplo.

5 Uso e ocupação do solo, transporte público, estradas vicinais, tratamento de água e esgoto, parques, asilos e a polícia.
} 
Figura 5: Municipalidades na Área de Planejamento Metropolitano de Toronto

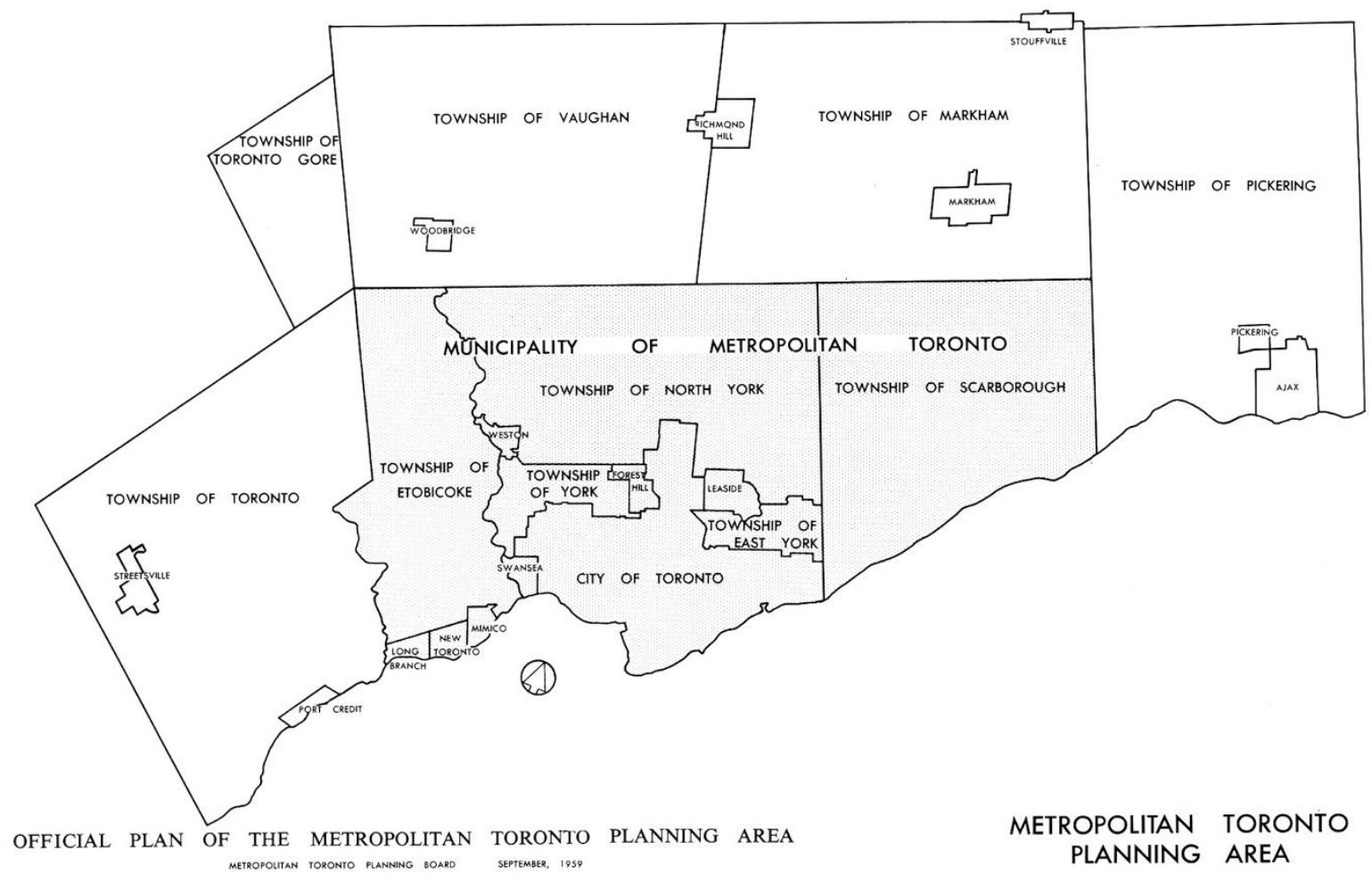

Fonte: Relph, 2014.

Figura 6: Imagem mostrando a mancha urbana da Metropolitan Toronto Planning Area

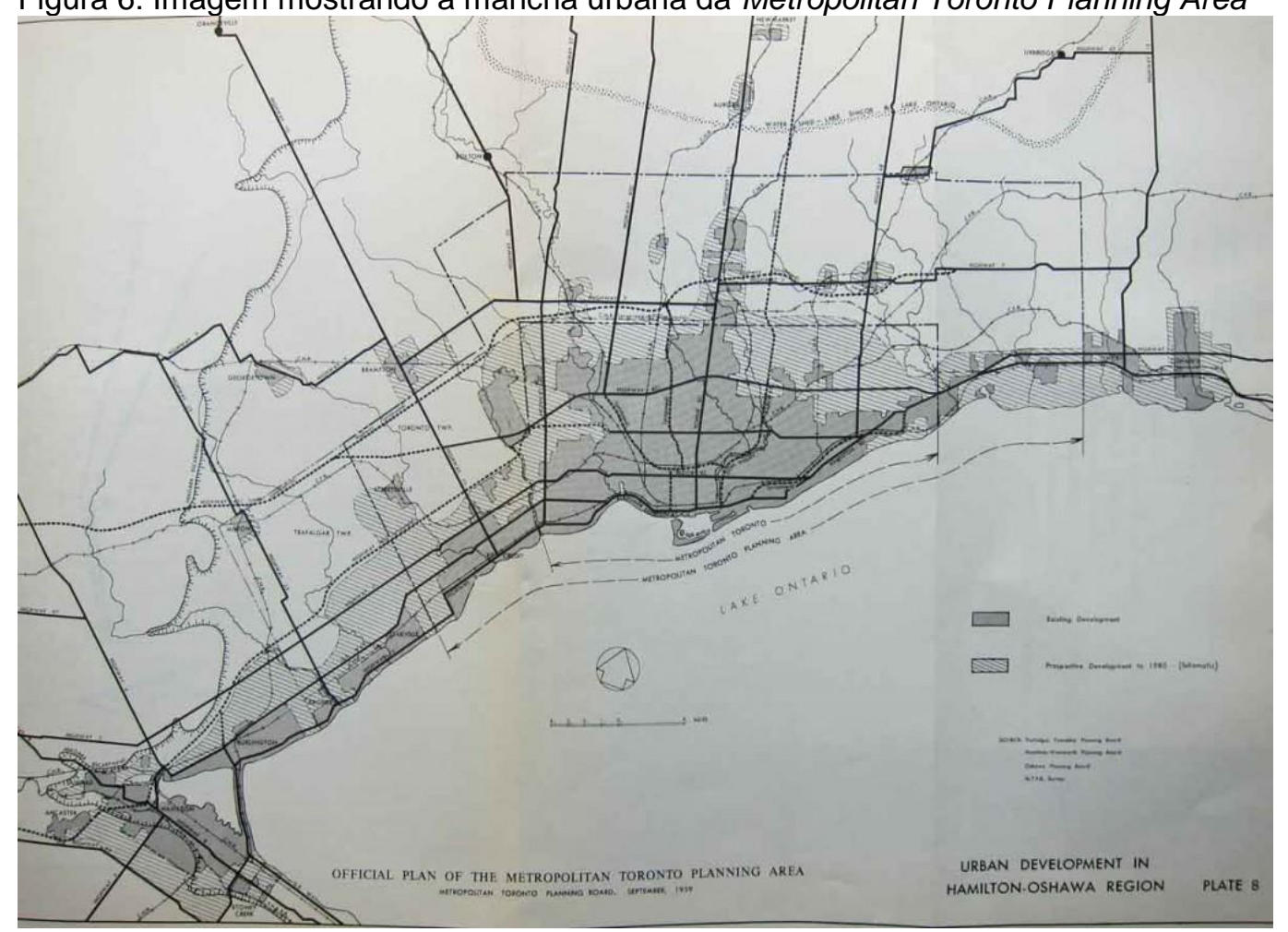

Fonte: Relph, 2014. 
Esta postura do governo provincial de Ontário acabou influenciando outras províncias canadenses a organizarem governos regionais, como a Metropolitan Winnipeg, na província de Manitoba, (criado em 1960 e dissolvido em 1972) e o Greater Vancouver Regional District, atualmente Metropolitan Vancouver, criado em 1967 pelo governo de Colúmbia Britânica.

Há, entretanto, autores que ponderam que a nível institucional, a escala metropolitana de planejamento foi considerada a partir de 1855, no Reino Unido, quando se definiu o Metropolitan Board of Works (1855), mais tarde transformado no London County Council (1889) (Cohen, 2013, p. 70), sendo que desta instituição originou-se o Greater London Council (1965). Nesta pesquisa, consideramos a entidade metropolitana britânica somente a partir de 1965, em contraposição ao autor citado, uma vez que entre 1855 e 1965 não havia uma área metropolitana londrina delimitada a qual se referir. Este posicionamento se dá pelo fato de após 1965 ter se dado sua transformação de uma entidade de planejamento regional (que a partir da Segunda Guerra Mundial passara a ter funções de planejamento urbano), em uma agência metropolitana, tendo seu recorte reduzido em termos territoriais para somente a aglomeração urbana, passando a ser responsável propriamente pela área metropolitana de Londres, então delimitada e resultante do London Government Act, de 1963.

Atualmente, Borja e Castells (1997) colocam que a organização política e administrativa das áreas metropolitanas varia de acordo com o país e mesmo dentro dos países (como no Brasil com a figura das RIDEs ${ }^{6}$ ), mas que existem basicamente três tipos: (i) há aquelas que tem algum tipo de governo, (ii) as que possuem algum tipo de coordenação (como agências) e (iii) aquelas com nenhum tipo de coordenação. Nesse sentido, como aponta Orellana (2013) "O debate sobre o fenômeno das áreas metropolitanas já cumpriu um século, quanto a considerá-la como uma realidade espacial mais complexa que a cidade tradicional e, pouco mais de meio século, a respeito de sua institucionalidade de governo." (ORELLANA, 2013, p. 1, traduzido da versão em espanhol).

A terceira perspectiva adotada, da delimitação das regiões metropolitanas como áreas de planejamento decorre dos primeiros estudos elaborados para cidades que, extrapolando seus limites administrativos, não poderiam ser analisadas de forma isolada.

${ }^{6}$ Regiões Integradas de Desenvolvimento: áreas metropolitanas que extrapolam os limites entre estados e são demarcadas e geridas pelo poder Federal. 
Segundo Blumenfeld (1956), ao longo da história o homem se dividiu entre viver na cidade e no campo, mas no mundo moderno as áreas metropolitanas não se confundem nem com um nem com o outro, ainda que possuam participação e influência em ambos. Prossegue o autor afirmando que as áreas metropolitanas diferem da cidade historicamente reconhecida em pelo menos dois aspectos: na função e na forma. Explica que nas eras pré-industriais a maioria das pessoas vivia no campo, por que era lá que o mundo do trabalho estava e que a cidade, historicamente local de encontro e de estabelecimento do poder político, religioso, comercial e cultural, tinha uma importante função de centralização das decisões.

Essa centralidade foi ampliada e se tornou cada vez mais complexa, originando as atuais áreas metropolitanas. Ao concentrar as duas funções anteriores, de liderança e trabalho (ou produção), acabaram com a clássica divisão entre a cidade e o campo, aprofundando, diversificando e especializando o trabalho.

Neste sentido, segundo Orellana (2013), a terminologia "área metropolitana" surgiu quando de forma progressiva se iniciou a constituição ao redor de uma cidade central um processo de urbanização caracterizado pela dependência funcional desta. Redefiniram-se sistematicamente os limites político-administrativos da cidade principal, se diferenciando de uma mancha urbana contida em um único município (pressupondo tendências ou factibilidade do fenômeno de conurbação) e mesmo de qualquer estrutura urbana tradicional até então conhecida. Ou, de forma simplificada, nas palavras de Van Treek (2006, p. 06) "O termo área metropolitana surgiu quando o termo cidade deixou de ser equivalente a urbano e foi necessário encontrar outro que desse conta das áreas urbanizadas no entorno da cidade central".

Como já indicado, interessa discutir a emergência da região metropolitana como unidade de planejamento, assim, o relevante, como apontam Orellana (2013) e Boix (2007), é entender que as áreas metropolitanas indicam a aproximação não apenas física, mas também de interações entre as cidades/municípios, tendo, portanto, impactos multiescalares e, consequentemente, não se expressando em mesma magnitude em todas as suas formas. A disseminação de tal terminologia pelo mundo possibilitou que em cada contexto se assumissem diferentes formas, variando histórica, cultural e politicamente em cada país (BORJA; CASTELLS, 1997), com enfoques particularmente distintos na maneira de definir tais recortes, sobretudo nos casos estadunidense, canadense e europeu. 
Assim, situa-se a origem da discussão sobre a delimitação de áreas metropolitanas no início do século XX, quando nos Estados Unidos a cidade de Nova York alcançou um milhão de habitantes e o Governo Federal começou a definir espaços metropolitanos, ainda que não tivessem como objetivo estabelecer uma nova escala de governo. Acabaram identificando-se então as grandes cidades e suas áreas de influência, delimitando os Industrial District (1905), os Metropolitan District (1910), as Industrial Areas (1920) e mais tarde as Labor Market Areas (1940), agrupadas por suas particularidades e definidas como unidades estatísticas homogêneas menores que os condados (BOIX, 2007; ORELLANA, 2013), que passaram a ser denominados entre os censos de 1900 e 1940 como Metropolitan Districts - figuras 7 e 8 (SHRYOCK, 1957).

Figura 7: Mapa da distribuição populacional dos Estados Unidos em 1940

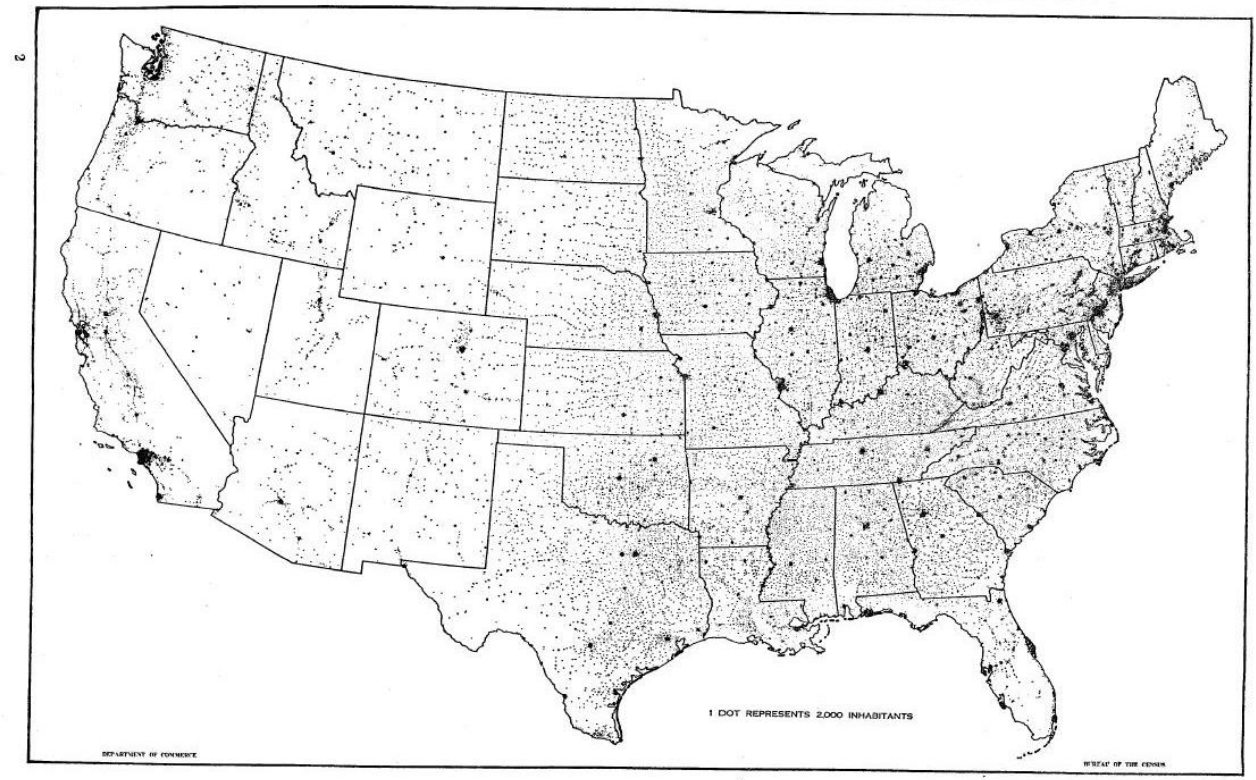

Fonte: U.S. Bureau of the Census, 2015. 
Figura 8: Mapa da distribuição dos Distritos Metropolitanos na década de 1930

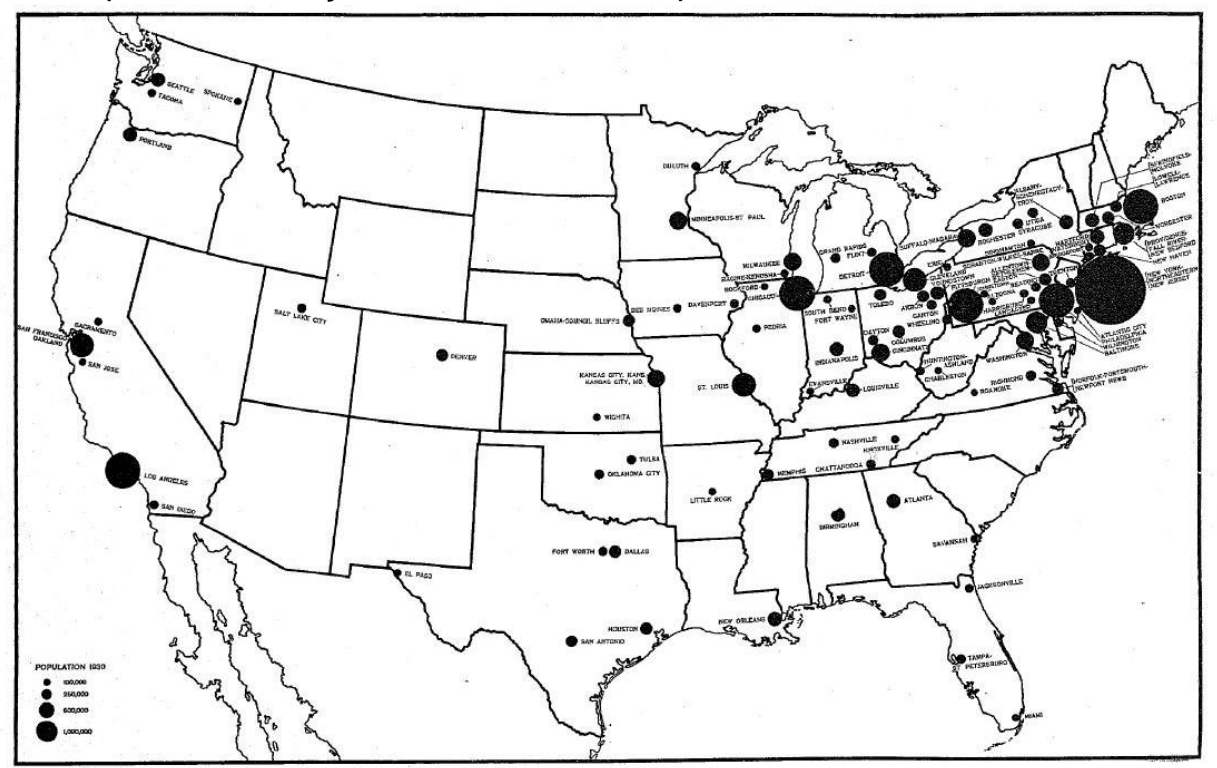

Fonte: U.S. Bureau of the Census, 2015.

A emergência do conceito se consolidou, de acordo com Shryock (1957), após a Segunda Guerra Mundial, quando o United States Bureau of the Census considerou que a clássica divisão em Metropolitan Districts, utilizada como recorte para o Censo de Fábricas e o Censo Populacional e de Residências, não dava mais conta da complexidade que as grandes áreas urbanas apresentavam.

Foi então criado um grupo de trabalho que em suas primeiras reuniões analisou uma série de assuntos, enfatizando as particularidades e o uso específico que poderia ser dado a cada área. O líder deste grupo era o estatístico norteamericano Morris H. Hansen (1910-1990), com atribuição de mediar e coadunar os conceitos trazidos pelos técnicos de diferentes campos do conhecimento, bem como responder às questões levantadas. Seu trabalho não esteve isento de críticas, uma vez que alguns pesquisadores consideravam positiva a manutenção dos distritos, já que a ideia de "área" pressupõe uma grande extensão, o que poderia resultar em definições grosseiras e generalistas. Contudo, ao se definir como área urbana, chegou-se à conclusão que a definição minuciosa dos limites físicos dos estabelecimentos urbanos seria melhor do que quando trabalhados em uma escala menor, como a dos condados (SHRYOCK, 1957).

A partir de 1947, de acordo com o autor, um comitê interinstitucional federal, a partir dos estudos já realizados teve como demanda definir as Standard Metropolitan Areas (SMA, figura 9). Dessa forma, a partir deste momento, uma série de estudos estatísticos foi realizada, sendo publicados individualmente para cada um dos 
antigos Distritos Metropolitanos. Os mais relevantes, de acordo com o autor, foram o Censo de Fábricas (1947), o Censo de Negócios (1948), o Censo Populacional e Residencial (1950) e dados compilados para o Censo Econômico de 1954.

Figura 9: Standard Metropolitan Areas em 1950

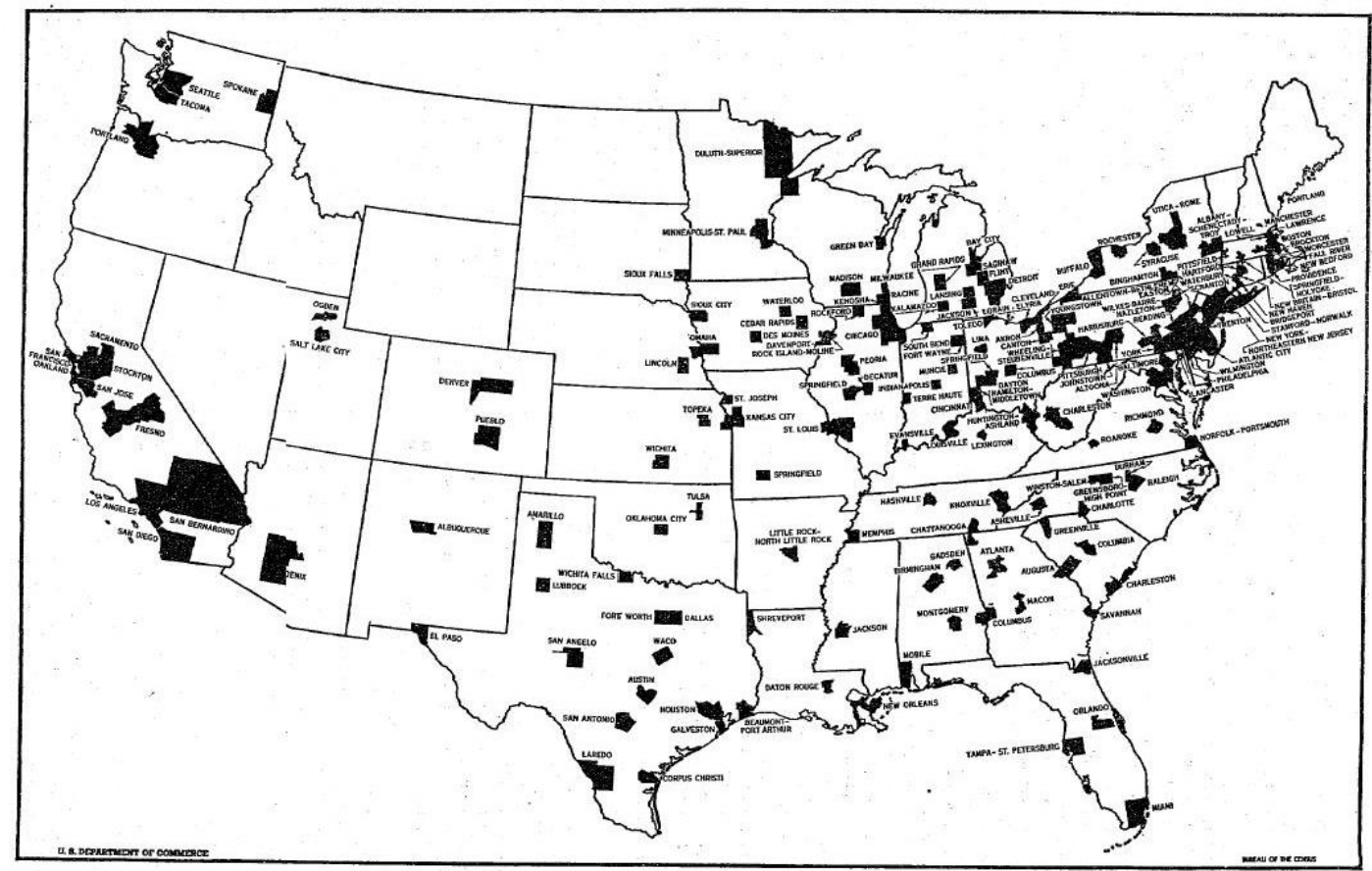

Fonte: U.S. Bureau of the Census, 2015.

No levantamento censitário de 1950, de acordo com Klove (1952), o United States Bureau of the Census se tornou o primeiro órgão oficial de gestão e planejamento a utilizar o termo "área metropolitana", quando publicou a divisão político-territorial dos Estados Unidos de acordo com os dados obtidos, momento onde cada município com mais de 50 mil habitantes foi definido como SMA, resultando em 172 áreas metropolitanas padrão7 (Klove, 1952, p. 96).

Esta definição populacional não esteve isenta de críticas, uma vez que se defendia a aproximação demográfica, pelo uso de unidades menores que os condados, utilizados como base para a elaboração dos Metropolitan Districts. Pelo viés econômico, contudo, se priorizava o uso do condado, pela dificuldade em se estabelecer estatística confiável a um nível menor ou dispor delas sem limitações ou sigilo.

Em 1948, o Interagency Committee on Standard Metropolitan Areas estabeleceu o condado como unidade, por ser a única forma possível de 
homogeneizar as estatísticas. Somente na região de New England ${ }^{8}$ havia outra definição para as SMA, pois os condados mantinham um estatuto diferente dos outros estados, onde os municípios e as cidades estavam mais bem definidos, permitindo que os dados fossem compilados localmente. Nesta região, as SMA foram definidas por um condado ou conjunto de condados que contivessem 150 hab/mil2 (240 hab/km²) ou 100 hab/mil², desde que apresentassem característica metropolitana de integração social e econômica com uma cidade central (SHRYOCK, 1957; BOIX, 2007).

A SMA foi definida então como uma "comunidade de trabalhadores não agrícolas que residiam em (e ao redor de) uma grande cidade, e estavam social e economicamente vinculados com uma cidade central, medido em função de fluxos pendulares e chamadas telefônicas", e, posteriormente, o de jornais (BOIX, 2007, p. 3).

Com este quadro, Orellana (2013) destaca que o histórico das áreas metropolitanas nos Estados Unidos pode ser separado em duas partes. A primeira, no início da delimitação das SMA, teve por fundamento a questão de que uma vez que não era possível que os planejadores urbanos respondessem pelas novas configurações urbanas e pela expansão e proliferação dos subúrbios, a nova escala pressupunha um planejamento territorial e gestão pública que compreendesse e estivesse em consonância com as novas condições urbanas. A segunda, supondo que determinados aspectos das SMA relativos aos processos de transformação urbana e territorial demandavam ações específicas para a gestão das políticas públicas, era necessário que se constituísse uma institucionalidade correspondente à sua escala. Não parecia aos órgãos do governo norte-americano nem factível e nem recomendável que houvesse uma governabilidade situada ou compartilhada entre o âmbito local e o regional.

Shryock, (1957) ao analisar o desenvolvimento do programa das SMA, identificou as questões e critérios específicos e gerais responsáveis pela introdução de tal conceito. Como visto, as áreas metropolitanas surgiram, como áreas estatísticas, baixo críticas de sua relevância, uma vez que os Censos utilizavam a escala de cidades e municípios (condados) em suas pesquisas e as áreas metropolitanas não seriam um substituto eficaz para medidas relativas a essas

\footnotetext{
${ }^{8}$ A região de New England, ou Nova Inglaterra, é uma das atuais divisões da região Nordeste dos estados Unidos, sendo formada pelos estados de Connecticut, Maine, Massachusetts, New Hampshire, Rhode Island e Vermont. Boston é a principal cidade da região. No Censo de 1950 era uma das regiões nas quais o órgão responsável dividia o país.
} 
escalas por ser muito ampla. Questionavam-se ainda quais seriam as regras para definir se um município estaria incluso em uma área ou ainda a grande quantidade de componentes necessária para analisar o que seria uma área metropolitana, entre outras controvérsias.

Portanto, nos Estados Unidos, se priorizou no início da década de 1950 um critério demográfico, mais especificamente o número de habitantes (mais de 50 mil), sendo a área metropolitana definida como aquela conformada por um ou mais municípios contíguos a um município central, com certo grau de integração social e econômica, o que, segundo Grau (1972, p. 13) resultou em uma ampliação tão grande do termo que "passou a ser aplicado também a centros urbanos que não apresentam características metropolitanas.", fenômeno parecido com brasileiro, onde a definição legal é muitas vezes contraditória ou não condizente com a extensão real do fenômeno metropolitano (FIRKOWSKI, 1999).

Para responder às principais críticas, de acordo com Shryock (1957), foram definidos indicadores para caracterizar o que seria metropolitano. Estes foram divididos em duas partes, sendo a primeira com dois critérios e a segunda com um critério. A primeira parte (figura 10, critérios 1 e 2), definia se o condado se tratava de um lugar de trabalho ou de um local de concentração de trabalhadores não agrícolas e seus dependentes, portanto com atividades eminentemente urbanas. Os dados para definir esses perfis foram:

Figura 10: Critérios 1 e 2 - Concentração e ocupação

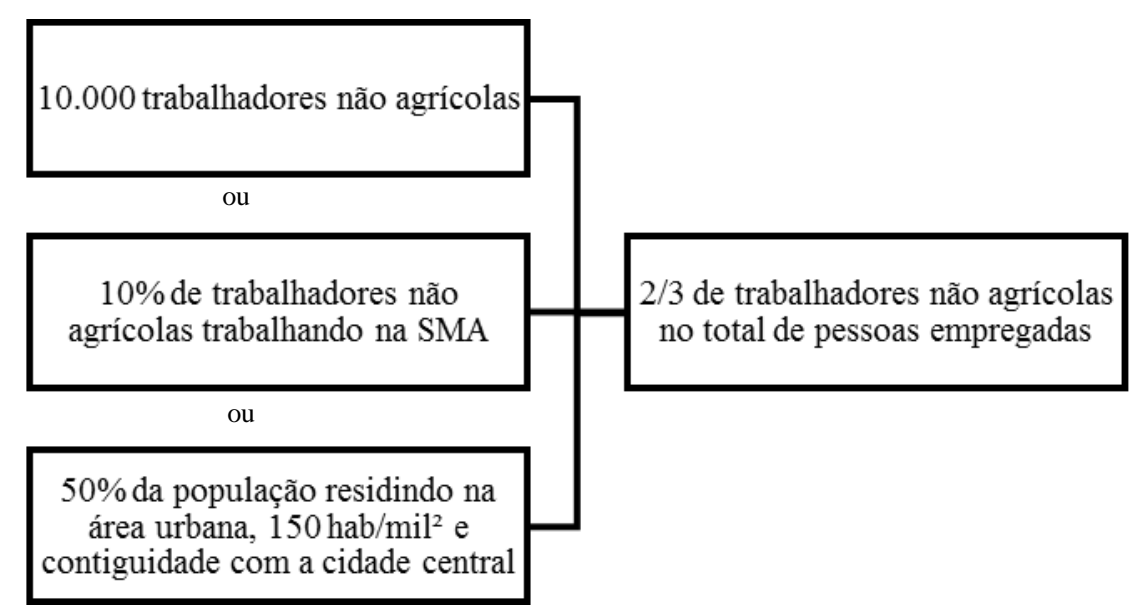

Fonte: Shryock (1957)

Elaborado pelo autor

1: O condado deveria conter 10.000 trabalhadores não agrícolas ou $10 \%$ de trabalhadores não agrícolas trabalhando na SMA, ou ter metade da população 
residindo na menor divisão política possível (a cidade) com uma densidade populacional mínima de 150 habitantes/mil2 e contiguidade com a cidade central.

2: Trabalhadores não agrícolas deveriam ser mais de dois terços do número total de pessoas empregadas no condado.

A segunda parte definia a integração econômica e social entre os condados e a cidade central, medidos pelos seguintes indicadores (figura 11, critério 3 ):

1: Cinquenta por cento ou mais de trabalhadores residindo na área urbana dos

Figura 11: Critério 3 - Integração econômica e condados contíguos e trabalhando no condado com a maior cidade da SMA, ou

2: Vinte e cinco por cento ou mais de pessoas trabalhando nos condados contíguos e residindo no condado que contém a maior cidade da SMA, ou

3: O número de chamadas telefônicas por mês para o condado que contém a maior cidade da SMA dos condados

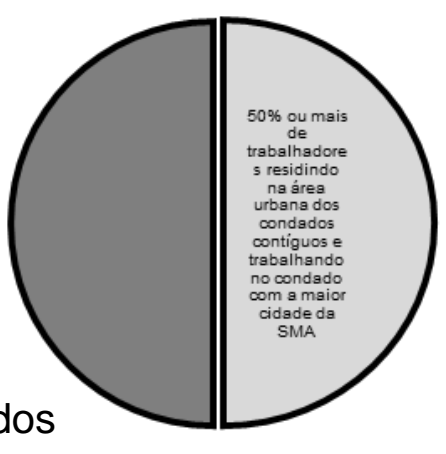
contíguos ser maior que quatro vezes o número de assinantes do condado contíguo.

Os critérios deveriam ser revistos a cada dez anos, objetivando reconhecer as mudanças econômicas, sociais, demográficas e tecnológicas. Dessa forma, em 1960, foram introduzidas mudanças na identificação das cidades centrais; além dos critérios populacionais e da proximidade física, o Bureau passou a considerar, para medir o caráter metropolitano dos municípios que integravam a área, que estes deveriam possuir $75 \%$ de população ativa não agrícola, densidade de 50 hab./milha ${ }^{2}$ e $15 \%$ dos trabalhadores realizando movimento pendular em direção à cidade central, não sendo considerados os fluxos multidirecionais.

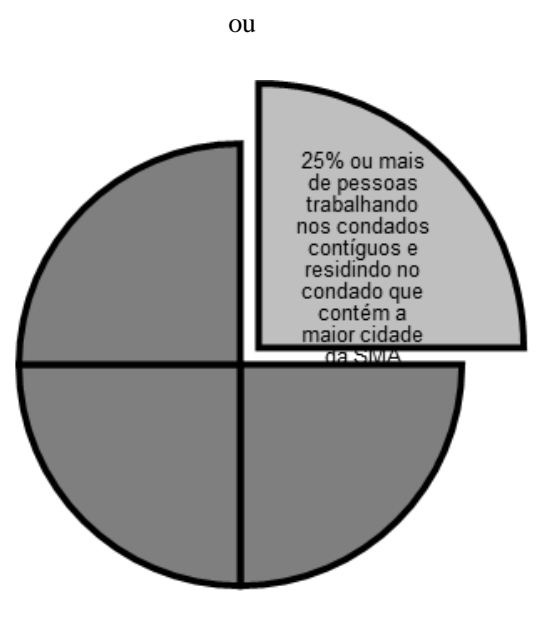

ou

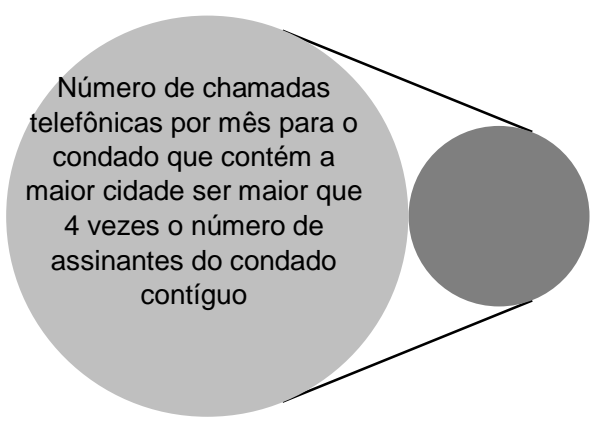


Em 1961, um estudo da Universidade da Califórnia utilizou os mesmos critérios para definir quais seriam as áreas metropolitanas no mundo todo, inclusive no Brasil, como mostra a figura 12 (UC, 1961).

Figura 12: Regiões Metropolitanas no Brasil definidas por estudo da Universidade da Califórnia, com base nos critérios estadunidenses

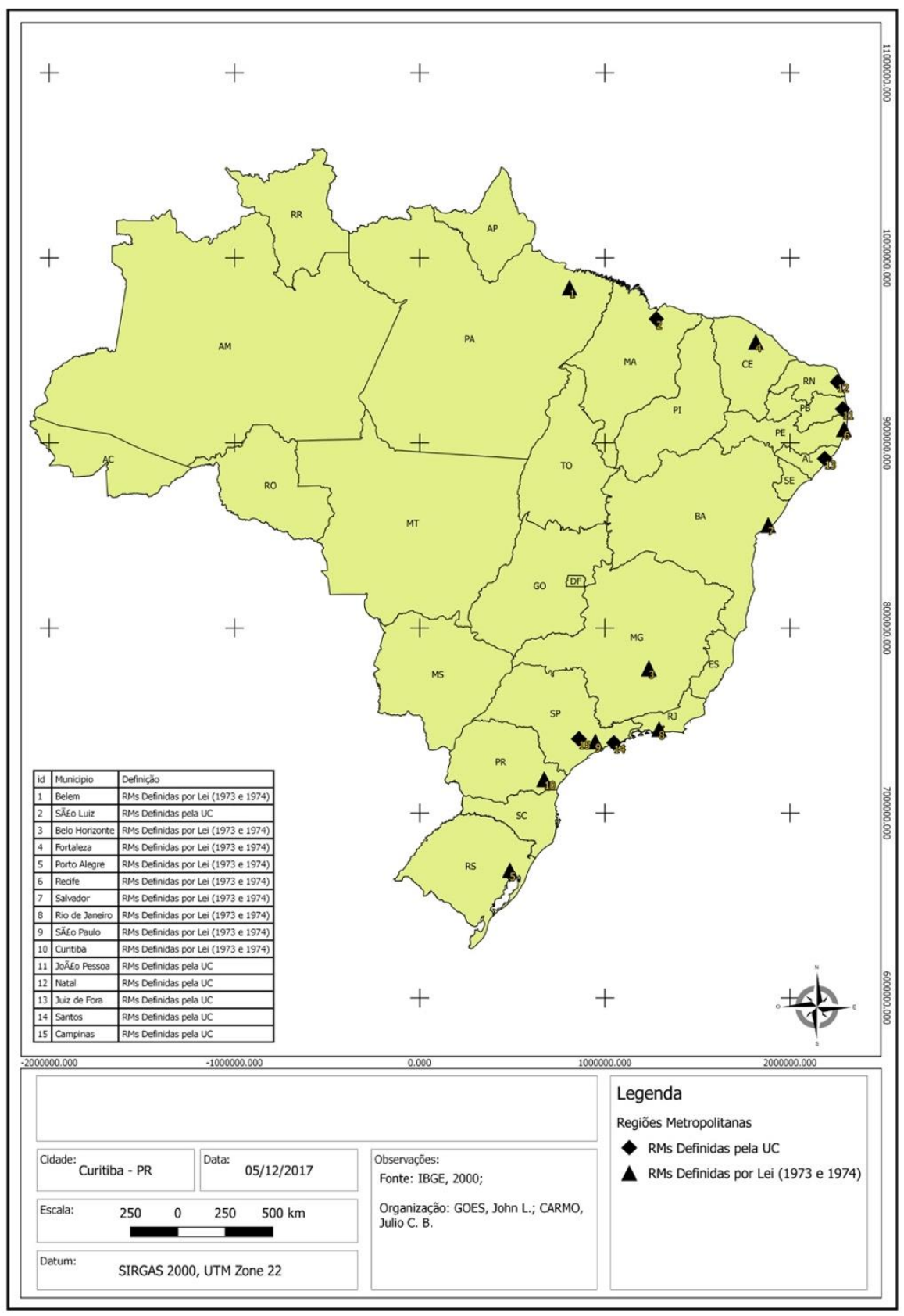

Fonte: CARMO, 2018

As RMs definidas por leis no Brasil também aparecem no estudo da UC. As que não foram reconhecidas pelas leis brasileiras são: Campinas, Santos, Juiz de Fora, Maceió, João Pessoa, Natal e São Luís. 
Ainda que menos utilizada internacionalmente, a expressão "região metropolitana" aparece no texto de Blumenfeld (1957), se confundindo com o conceito de área metropolitana, tal qual ocorre no Brasil (GALVÃO, 1969; VILLAÇA, 2001). Relata o autor que

Some observers of the urban scene in the United States think that the metropolis is already passé, that it is being engulfed by a larger unit, the "urban region", such as that which extends from Boston to Washington. However, there is really nothing new in the string of cities lined up along a favorable trade route or in the fact that the area between such cities is more intensely developed than the surrounding country. what is new in the character of the individual units out of which the "urban region" is composed. This unit is no longer a "city": it is a "metropolitan region", though it is still called by the name of the historic city that forms its core: New York or Philadelphia, Montreal or Toronto. (BLUMENFELD, 1957, p. 235) ${ }^{10}$

Prossegue o autor afirmando que a região metropolitana é uma nova forma de assentamento humano, jamais existente na história. Durante milhares de anos o homem se dividiu entre o campo e a cidade, que seriam opostos e complementares, se dirigindo agora para as regiões metropolitanas, que unem ambos. Como já dito, esta mesma definição foi utilizada pelo autor em texto de 1956 para definir o que seria uma área metropolitana.

Uma série de autores (AZEVEDO, 1976; VILLAÇA, 2001; PILLOTO, 2010) chamam atenção para o fato de os urbanistas e planejadores preferirem a denominação "área metropolitana" ao invés de região metropolitana, que seria toda área polarizada por uma metrópole. Nas palavras de Azevedo (1976, p. 16) "A região compreende um círculo territorial maior, profundamente influenciado pela metrópole, mas que não chega a confundir-se com esta”. Contudo, ainda assim, no caso brasileiro o legislativo adotou Região Metropolitana para definir a unidade de planejamento.

As regiões metropolitanas indicam que a divisão politico-administrativa deixou de corresponder aos municípios existentes, ou seja, o fenômeno urbano e a unidade territorial deixaram de ser correspondentes, tornando "obsoleta e irreal a tradicional

\footnotetext{
${ }^{9}$ A expressão "Urban Region" utilizada pelo autor estaria mais para o conceito contemporâneo de "megalópole" do que "região metropolitana".

10 "Alguns observadores da cena urbana nos Estados Unidos pensam que a metrópole já é coisa do passado, que está sendo engolida por uma unidade maior, a 'região urbana', como a que se estende de Boston a Washington. No entanto, não há realmente nada de novo na série de cidades alinhadas ao longo de uma rota de comércio favorável ou no fato de ser a área entre essas cidades a mais intensamente desenvolvida em todo o país. O que é novo é o caráter das unidades individuais de que a 'região urbana' é composta. Esta unidade não é mais uma 'cidade': é uma 'região metropolitana', embora ela ainda seja chamada pelo nome da cidade histórica que forma seu núcleo: Nova York ou Filadélfia, Montreal ou Toronto." Tradução nossa.
} 
divisão municipal" (AZEVEDO, 1976, p. 14), ou ainda que "a área metropolitana é uma única cidade sob todos os aspectos: físico, econômico, social e cultural, menos um - o político-administrativo.". Concorda com as palavras de Villaça (2001), que afirma que a região metropolitana é o espaço onde "a uma única cidade correspondem vários municípios.". De forma a evitar tal polêmica, nesta pesquisa os termos "área metropolitana" e "região metropolitana" serão utilizados como sinônimos.

Outro ponto que gera controvérsias desde as experiências pioneiras são os diferentes critérios para o que seria uma área metropolitana, algo que diversos autores $^{11}$ tem se dedicado a analisar e compilar dados. No Canadá, por exemplo, após a experiência de Toronto, as áreas metropolitanas passaram a ser definidas por aglomerações formadas quando a cidade núcleo atinge 50 mil habitantes e uma população total polarizada de pelo menos 200 mil habitantes.

O caso europeu é mais complexo, uma vez que o modelo de organização territorial varia de país para país, alterando de modelos unitários e centralizados (França, Portugal), federais (Alemanha), comunitários (Espanha), e descentralizados (Inglaterra, Suécia) (Orellana, 2013), além de os países não reconhecerem a área metropolitana para efeitos estatísticos (Rodriguez; Oviedo, 2001). Isso se deve ao fato de que, como destaca Boix (2007, p. 9), na Europa muitas áreas metropolitanas não se formarem por descentralização de população a partir de uma cidade central, mas sim pelo aumento da interação econômica entre um conjunto de subcentros (não necessariamente conurbados).

No caso inglês, a visão econômica é a predominante, se estabelecendo áreas metropolitanas em razão dos mercados de trabalho locais, considerando o movimento pendular em direção ao município central. $\mathrm{Na}$ Espanha $^{12}$, desde a década de 1960 o Ministério da Habitação, considera como critérios de definição das áreas metropolitanas a existência de uma cidade central de pelo menos 50.000 habitantes e a vinculação econômica e social entre a cidade central e os municípios periféricos, com população mínima polarizada de 100.000 habitantes (RODRíGUEZ; OVIEDO, 2001). Os trabalhos de Serra et al. (2002) e Rozenblat; Cicille (2003), trabalhando com metodologias diferentes, identificaram 80 e 180 áreas metropolitanas na Europa respectivamente, apresentadas nas figuras 13 e 14 .

\footnotetext{
${ }^{11}$ Como Orellana (2013); Sorribes (1999); Rodríguez; Oviedo (2001); Rozenblat; Cicille (2003) e Boix (2007)

12 Boix (2007) apresenta uma série de metodologias utilizadas na Espanha e que definem diferentes áreas metropolitanas. A utilizada neste texto refere-se à oficial.
} 
Figura 13: Aglomerações Metropolitanas na Europa

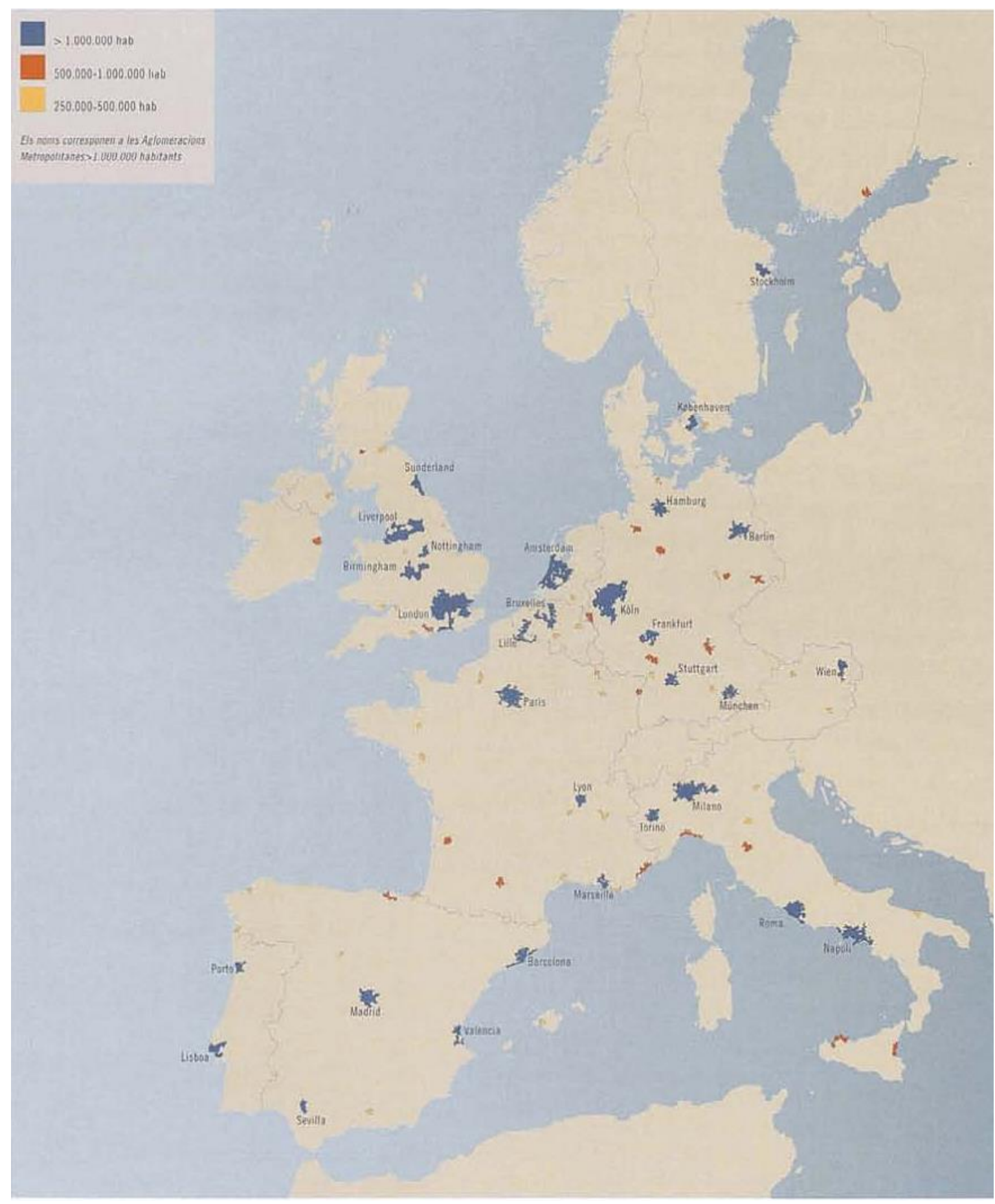

Fonte: SERRA, J.; OTERO, M.; RUIZ, Y.R., 2002. 
Figura 14: Aglomerações Metropolitanas na Europa

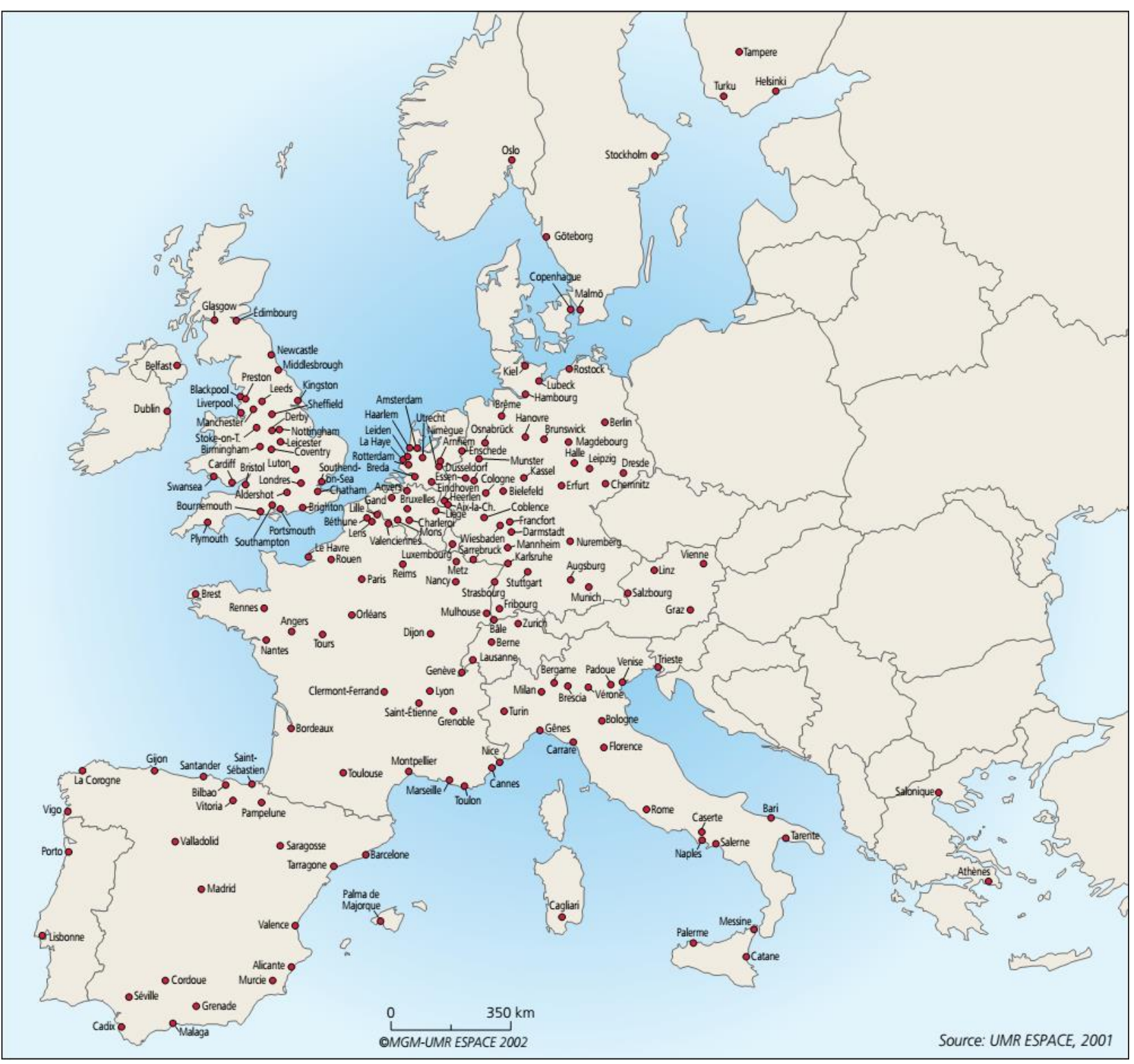

Fonte: Rozenblant, C.; Cicille, P. ,2003.

Mostram tais autores que ainda que existam uma série de particularidades, alguns critérios são consenso, como a necessidade de um núcleo central com população maior que uma determinada (geralmente superior a 50.000 habitantes), que o núcleo polarize outros municípios ou administrações locais e um percentual de força de trabalho dos municípios periféricos estabeleça movimento pendular diário com a cidade central. Outros critérios como o percentual de população vinculada a atividades urbanas, população mínima da área metropolitana entre outros, são menos comuns. 


\section{Considerações Finais}

Consolidada a região metropolitana como unidade de planejamento, a partir da década de 1980 houve uma ressignificação da política metropolitana em diversos países, sobretudo pela aplicação da ideologia do neoliberalismo. No Reino Unido, por exemplo, o governo de Margareth Thatcher suprimiu o governo regional londrino em 1986. No Canadá, a divisão do poder regional em dois níveis estabelecido em 1953, onde os representantes eram eleitos por voto direto, foi substituída por um único nível, a estrutura única da cidade de Toronto, de forma a diminuir os gastos públicos durante a década de 1990 (BOOTHROYD, 2010).

Contudo, se a década de 1980 foi de desmonte das instituições metropolitanas, no fim da década de 1990 e nos anos 2000 o tema retomou importância, atraindo a atenção de governos, pesquisadores e instituições no mundo ocidental. Trabalhos como os da OCDE (2001a; 2001b) sobre as regiões metropolitanas, ou ainda, novamente, no caso de Londres, por exemplo, onde um novo regime foi criado, o Greater London Authority, reestabelecendo o governo metropolitano abolido por Thatcher (SIMMONS, 2000). Ainda na Europa, foi criado o Metrex $^{13}$, em 1996, e em 1999 foi publicada a Carta Magna Metropolitana europeia.

Assim, considerando a experiência internacional, é possível reconhecer que o planejamento metropolitano obedeceu a seguinte sequência: elaboração de planos centrados em metrópoles, seguido da delimitação de áreas metropolitanas como áreas estatísticas, econômicas e de planejamento e por fim a criação de instituições que respondessem pelo planejamento na nova escala, ainda que mantenham distintas formas de gestão e de definição de tais áreas. O conceito, ainda que não unânime, é utilizado em diferentes países, com diversas formas de organização administrativa, de forma que o planejamento das áreas metropolitanas hoje se mostra tão premente que não há como ser ignorado pelas autoridades e pesquisadores.

${ }^{13}$ Metrex é uma rede constituída por 119 regiões e áreas metropolitanas (áreas urbanas com influência sobre uma população de mais de 500.000 habitantes) existentes na Europa (Ocidental e Oriental). 


\section{REFERÊNCIAS}

AZEVEDO, E.A. A região metropolitana no Brasil e seu regime jurídico. São Paulo (estado). O Desafio Metropolitano. Secretaria de Negócios Metropolitanos/Emplasa, Cap. II, p. 1436. São Paulo, 1976.

BENKO, G. A ciência regional. Lisboa, Celta, 1998.

BLUMENFELD, H. Metropolitan Area Planning. Journal of the Toronto Board of Trade, vol. 46, no 3 (março de 1956), p. 16-19. In: Spreiregen, P.D. 1967. The Modern Metropolis: its origins, growth, characteristics and planning. Selected essays by Hans Blumenfeld. MIT Press, Cambridge, p. 79-83.

. Scale in the Metropolis. The Canadian Architect, vol II, no 9, Setembro de 1957, p. 46-48 In: Spreiregen, P.D. 1967. The Modern Metropolis: its origins, growth, characteristics and planning. Selected essays by Hans Blumenfeld. MIT Press, Cambridge, p. 235-241.

BOIX, R. Concepto y delimitación de áreas metropolitanas: una aplicación a las áreas metropolitanas de España. Seminário Las grandes áreas metropolitanas españolas em uma perspectiva comparada. Sevilla, abril/2007. [Online] Disponível em http://urban.uab.es/references/2007/07002.pdf acesso em setembro/2014.

BOOTHROYD, P. Construindo capacidades para a governança metropolitana. In: Klink, J. (org.) Governança das metrópoles: conceitos, experiências e perspectivas. São Paulo, Annablume, 2010, p. 117-126.

BORJA, J.; CASTELLS, M. Local y global. La gestión de las ciudades en la era de la información. Madrid, United Nations for Human Sttlements/Taurus/Pensamiento, 1997.

CABRAL, D.C. Von Thünen e o abastecimento madeireiro de centros urbanos préindustriais. Revista Brasileira de Estudos de População, 28(2), 405-427, 2011. Disponível em http://www.scielo.br/scielo.php?script=sci_arttext\&pid=S0102$30982011000200010 \&$ Ing=en\&tlng=pt. 10.1590/S0102-30982011000200010. Acesso em abril de 2015.

CARMO, J.C.B. A Serra Pelada do Urbanismo: planejando a Região Metropolitana da Cidade Modelo (Curitiba e Região 1961-2015). Tese (Doutorado em Arquitetura e Urbanismo), Universidade de São Paulo, São Carlos, 2018.

COHEN, J.L. O futuro da Arquitetura desde 1889: uma história mundial. São Paulo, Cosac Naify, 2013.

$D A L C O, F$. et al. De los Parques a la Region. Ideologia Progresista y Reforma de la Ciudad Americana. Ciucci, G., Dal Co, F., Manieri-Elia, M., Tafuri, M. La Ciudad Americana. Barcelona, Ed. Gustavo Gili, 1975.

FIRKOWSKI, O.L.C.F. Porque as regiões metropolitanas no Brasil são regiões mas não são metropolitanas. Revista Paranaense de Desenvolvimento, Curitiba, n.122, p.19-38, jan./jun. 2012.

GALVÃO, M. V. et. al. Áreas de pesquisa para determinação de áreas metropolitanas. Revista Brasileira de Geografia, Rio de Janeiro, v. 31, n. 4,1969, p. 53-128.

GRAU, E.R. Aspectos jurídicos do planejamento metropolitano. Tese (Direito), USP, 1972. 
GOMES, P C. C. O conceito de região e sua discussão. In: Castro, I. E.; Gomes, P. C.; Corrêa, R. L. Geografia: conceitos e temas. Rio de Janeiro, Bertrand Brasil, 1995, p. 4976.

HALL, P. Cidades do Amanhã - Uma história intelectual do planejamento e do projeto urbanos no século XX, São Paulo, Perspectiva, 2013.

KLOVE, R.C. The Definition of Standard Metropolitan Areas. Economic Geography, Worcester, Clark University, vol. 28, no 2, Abril/1952, p. 95-104.

LENCIONI, S. Referências analíticas para a discussão da metamorfose metropolitana contemporânea. In: Lencioni, S.; Vidal-Koppmann, S.; Hidalgo, R.; Pereira, P.C.X.. (Org.). Transformações sócio-territoriais nas metrópoles de Buenos Aires, São Paulo e Santiago. São Paulo, Paim, 2011, p. 51-64.

NEW DEAL NETWORK. TVA: the origins of the Tennessee Valley Authority. Disponível em http://newdeal.feri.org/tva/tva01.htm Acesso em abril de 2015.

OFFICE OF MANAGEMENT AND BUDGET. Alternative Approaches to Defining Metropolitan and Nonmetropolitan Areas. Federal Register, v. 63, n. 244, dez. 1998.

ORELLANA, A. Gobiernos Metropolitanos para Chile: la necesidad versus la factibilidad, Centro de Políticas Públicas, Pontifícia Universidad Católica de Chile, ano 8, n.63 nov. 2013. Disponível em http://politicaspublicas.uc.cl/wpcontent/uploads/2015/02/serie-no-63-gobiernos-metropolitanos-para-chile-la-necesidadversus-la-factibilidad.pdf Acesso em outubro de 2014.

PILOTTO, A. S. Área metropolitana de Curitiba. Um estudo a partir do espaço intraurbano. Dissertação (Mestrado em Planejamento Urbano Regional) - FAU, Universidade de São Paulo, São Paulo, 2010.

QUINTO JUNIOR, L.P. O papel da historiografia como instrumento de avaliação do surgimento da gestão urbana contemporânea. RUA, Revista de Arquitetura e Urbanismo. UFBA, Vol. 3, nำ 1990, p. 62-75. [Online] Disponível em http://www.portalseer.ufba.br/index.php/rua/article/view/3106 acesso em novembro de 2014

RELPH, E. Toronto: Transformations in a City and its Region. Disponível em http://www.torontotransforms.com/ Acesso em abril de 2015.

RODRÍGUEZ, A.; OVIEDO, E. Gestión urbana y gobierno de áreas metropolitanas. Santiago, CEPAL, División de Medio Ambiente y Assentamientos Humanos, 2001.

ROZENBLANT, C.; CICILLE, P. Les villes éuropeénnes: analyse comparative. Datar, 2003. Disponível em http://www.mgm.fr/ARECLUS/page_auteurs/rozen_veuro.pdf Acesso em outubro 2014.

SERRA, J.; OTERO, M.; Y R. RUIZ. Grans aglomeracions metropolitanes Europees. IRMB. 2002.2 Disponível em http://www.raco.cat/index.php/PapersIERMB/article/view/105481/164808 Acesso em outubro de 2014.

SHRYOCK, H.S.The Natural History of Standard Metropolitan Areas. American Journal of Sociology, Chicago, The University of Chicago Press, vol. 63, №. 2, Setembro/1957), p. 163-170. 
SIMMONS, M. El caso de Londres: Gobierno y sistemas de gestión de planeamento. Urban, Madri, no 5, 2000-2001, p. 40-49.

SORRIBES, J. Estudio comparativo sobre 17 áreas metropolitanas. Informe de investigación. Barcelona, 1999.

UC. Las Areas Metropolitanas del Mundo. México DF, Editorial Continental, 1961.

URBAN OMNIBUS. Innovation and the American Metropolis. Disponível em http://urbanomnibus.net/2010/03/innovation-and-the-american-metropolis/ acesso em outubro de 2014.

U.S. BUREAU OF THE CENSUS. Metropolitan Areas. Disponível em https://www.census.gov/history/www/programs/geography/metropolitan_areas.html Acesso em fevereiro de 2015.

VAN TREEK, E. V. Las áreas metropolitanas. reflexión, evolución y casos de estudios Urbano, vol. 9, núm. 14, nov., p. 4-13 Universidad del Bío Bío Concepción, Chile, 2006.

VILLAÇA, F. Espaço intra-urbano no Brasil. São Paulo: Studio Nobel: FAPESP: Lincoln Institute, 2001.

\section{NOTAS DE AUTOR}

\section{CONTRIBUIÇÃO DE AUTORIA}

Julio Cesar Botega do Carmo - Concepção. Coleta de dados, Análise de dados, Elaboração do manuscrito, revisão e aprovação da versão final do trabalho

\section{FINANCIAMENTO}

Coordenação de Aperfeiçoamento do Pessoal de Ensino Superior (CAPES). Número do Processo: 1452488. Universidade de São Paulo (São Carlos).

\section{CONSENTIMENTO DE USO DE IMAGEM}

Não se aplica.

\section{APROVAÇÃO DE COMITÊ DE ÉTICA EM PESQUISA}

Não se aplica.

\section{CONFLITO DE INTERESSES}

Não se aplica.

\section{LICENÇA DE USO}

Este artigo está licenciado sob a Licença Creative Commons CC-BY. Com essa licença você pode compartilhar, adaptar, criar para qualquer fim, desde que atribua a autoria da obra.

HISTÓRICO - uso exclusivo da revista

Recebido em: 28-02-2018

Aprovado em: 02-07-2018 